\title{
Editorial
}

\section{Cadaveric Kidney Transplantation}

A cadaver transplant is an organ taken from a brain dead person and transplanted into a patient. Such transplants give a new lease of life to patients. For a patient awaiting a transplant, the first option is live transplant for which doctors look for a donor who is a relative. If that doesn't match, the patient has to wait for a cadaver donation.

Renal replacement therapy (RRT) has a vital role in the treatment of severe acute kidney injury (AKI) and end-stage renal disease. Most patients with chronic kidney disease (CKD) stage 4-5( End stage Renal Failure) require RRT. Three choices for renal replacement therapy are available for patients with end-stage renal disease: conservative care and symptomatic, haemodialysis, kidney transplant (from a living or cadaveric donor). Dialysis is very costly and do not serve all the renal function. Moreover, morbidity and mortalities are more than transplantation ${ }^{1}$. Therefore, kidney transplantation is the choice of treatment bellow 60 years. Unfortunately, organ shortage is the main obstacle in the process of transplantation. Hence, world wide cadevaric kidney transplantation is gaining popularity. The shortage of organs for transplantation, is becoming more critical every year. Because of improvements in transplantation procedures and the advent of immunosuppressive therapies in the early 1980s, increasingly large numbers of patients can now be benefited from organ transplantation².

On December 23, 1954, Dr. Joseph Murray and the medical team at Boston's Peter Bent Brigham Hospital gave a kidney to a seriously ill, 23-yearold man in the first successful long-term transplant of a human organ ${ }^{3}$. Since then, transplants have saved more than 400.000 lives each day. About 15 people die due to non-availability of organs. Organ shortage is the main limitation in saving lives of critically ill patients ${ }^{4}$.

Deceased donation \& transplantation programme actually means, coordination related to deceased donor, a team related to multi -organ retrieval and preservation, distribution, transportation and transplantation of organs. Deceased donors rate per million population per year in USA is 21, in Europe 15:9, in South America 2.6, in Asia Less than $\mathrm{I}^{4}$. In Bangladesh, physicians are preparing to develop infrastructure to start the programme.

In conclusion, deceased organ donation programme needs dedication of a team and can be made by investment in renal replacement programme by the Government supported by NGOs, engagement of civil society, involvement of print and electronic media for awareness, priority to enhance ICU units in major hospitals, doctors as coordinators with involvement of intensivists, anesthetists, a trained central coordinator who will perform, 24 hour coordination duty desk ground work to establish new legislation for deceased transplantation, public awareness campaigns, donor network with quality assurance. Hence, organ procurement is a coordinated team work and every stakeholder is to come forward to save life of critically ill kidney patients.

\section{Prof. Shahanaz Begum \\ Professor, Anatomy, NICVD, Dhaka \\ $\&$ \\ Editor, Bangladesh Journal of Anatomy}

\section{References:}

1. Morris PJ. Kidney Transplantation. Fifth edition, W.B.Saunders Company. 2001.

2. Owen JR WF, Pereira BJG, Sayegh MH. Dialysis and Trasplantation. First edition, W.B.Saunders Company. 2000.

3. Joseph ME. Surgery of the Soul - Science history publications. First edition, Watson. Pub. Intl. 1 June 2004.

4. Shorff S. Coordinating deceased donation \& transplantation programme. Fourth Conference of Nephrology, Urology \& transplant society of the SAARC countries. 13-14 December 2011. 